\title{
Long-Term Corrosion/Oxidation Studies Under Controlled Humidity Conditions
}

Greg Gdowski

October 13, 1997

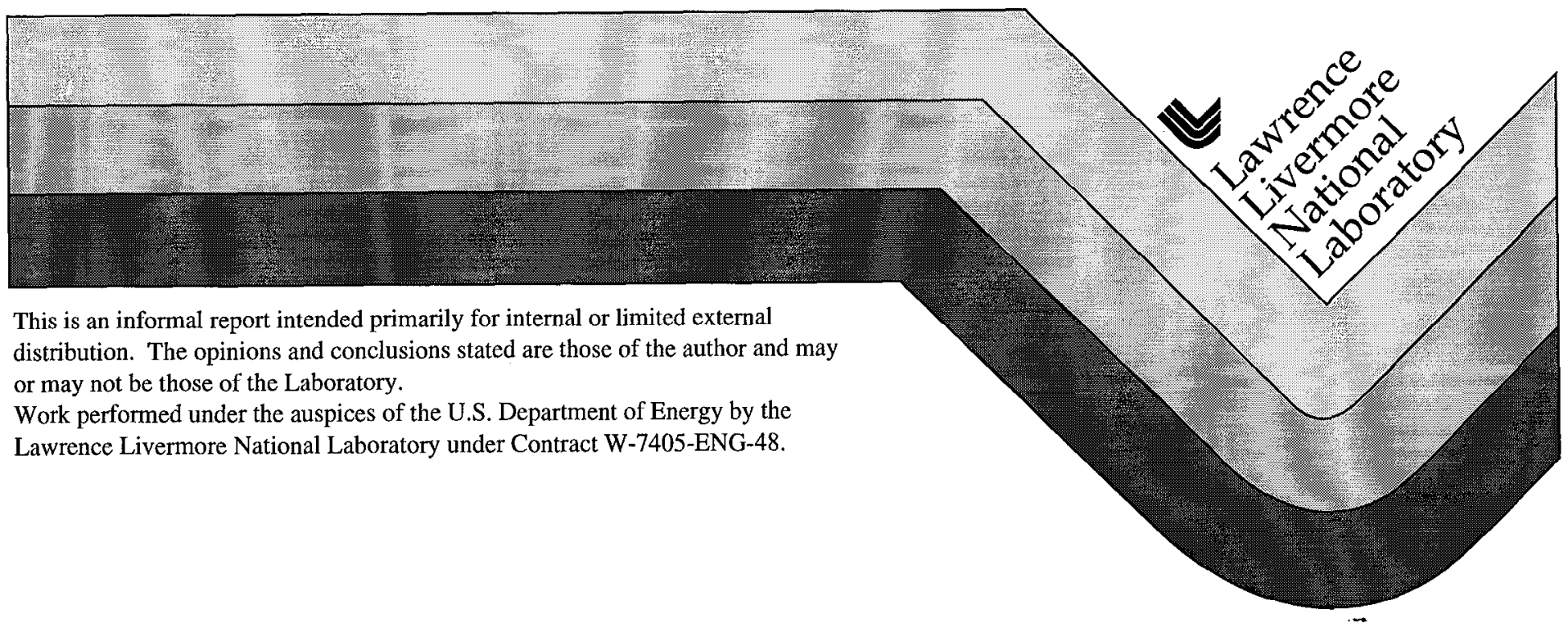




\section{DISCLAIMER}

This document was prepared as an account of work sponsored by an agency of the United States Government. Neither the United States Government nor the University of California nor any of their employees, makes any warranty, express or implied, or assumes any legal liability or responsibility for the accuracy, completeness, or usefulness of any information, apparatus, product, or process disclosed, or represents that its use would not infringe privately owned rights. Reference herein to any specific commercial product, process, or service by trade name, trademark, manufacturer, or otherwise, does not necessarily constitute or imply its endorsement, recommendation, or favoring by the United States Government or the University of California. The views and opinions of authors expressed herein do not necessarily state or reflect those of the United States Government or the University of California, and shall not be used for advertising or product endorsement purposes.

This report has been reproduced directly from the best available copy.

Available to DOE and DOE contractors from the Office of Scientific and Technical Information P.O. Box 62, Oak Ridge, TN 37831

Prices available from (423) 576-8401

Available to the public from the National Technical Information Service

U.S. Department of Commerce 5285 Port Royal Rd.

Springfield, VA 22161 
University of California

¿L Lawrence Livermore

No.:

AP $E-20-59$

YUCCA MOUNTAIN PROJECT

Activity Plan

Revision: $\quad 0$

Change Notice: CN E-20-59-0-2

Page: 1 of 15

Subject: Long-Term Corrosion/Oxidation Studies Under Controlled Humidity Conditions

AUTHOR:

Greg Gdowski

Training Required: Yes $\square$ No

Comments:

Editorial change only.

REVISION HISTORY

Rev. No. CN No. Effective Date: Description of Revision/CN

0

01/13/97

Original issue

$0 \quad$ CN E-20-59-0-1 04/04/97

Text changes for clarification; repagination. Affects Title Page, pages $\mathrm{i}, \mathrm{ii}$, and pages 1 through 12 of 12.

$0 \quad C N E-20-59-0-2 \quad 10 / 13 / 97$

Minor editorial changes only; repagination. Affects Title Page, pages $i$, ii, and pages 1 through 10 of 12.

APPROVALS:

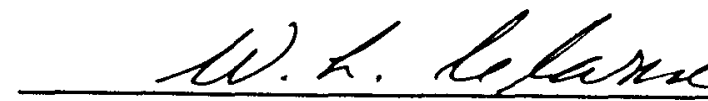

W.L. Clarke, CRWMS LLNL Manager
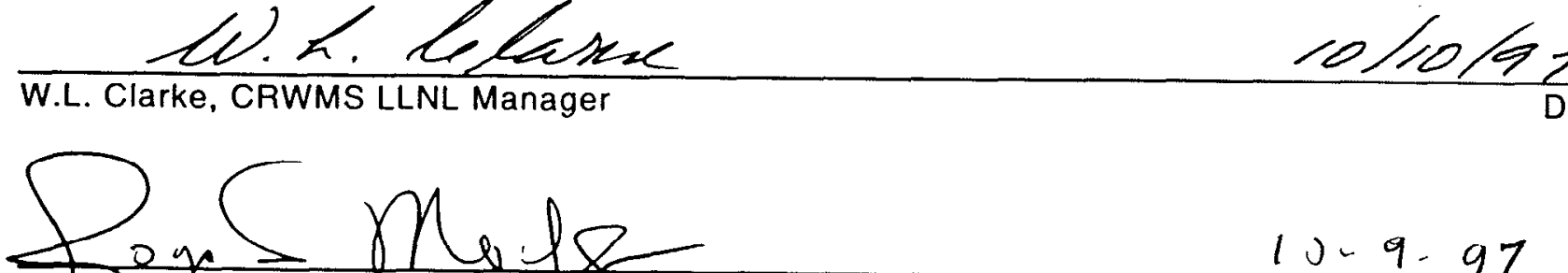

$10-9$

R.E. Monk. M\&O LLNL Engineerhg Assurance Manager
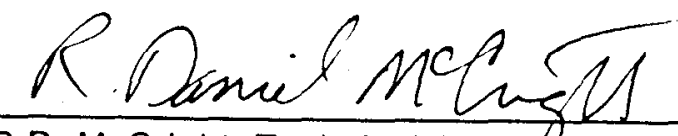
Long-Term Corrosion/Oxidation Studies Under Controlled Humidity Conditions Activity Plan E-20-59

YMP WBS Element 1.2.2.5.1

LLNL-YMP Metal Barrier Selection and Testing

Lawrence Livermore National Laboratory

Revision 0 
Page

$1.0 \quad$ SCIENTIFIC INVESTIGATION PLAN ...................................

1.1 Activity Identity ...................................................

1.2 Responsibilities .............................................

2.0 SCOPE, PURPOSE, AND OBJECTIVES..............................

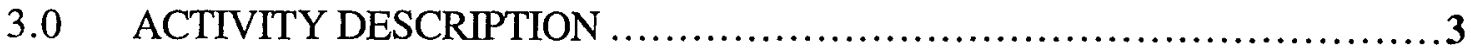

3.1 Technical and Readiness Reviews...............................4

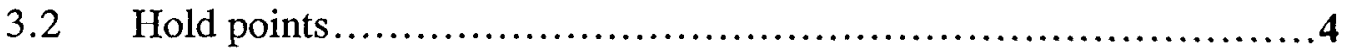

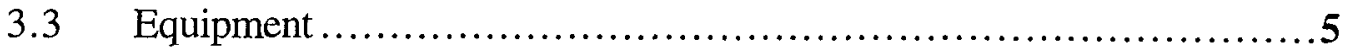

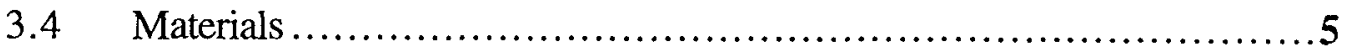

3.5 Special Environmental Conditions...............................6

3.6 Spccial Training/Qualification Requiréments.......................6

3.7 Quality Assurance Program .........................................6

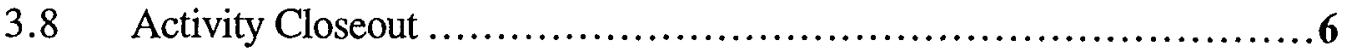

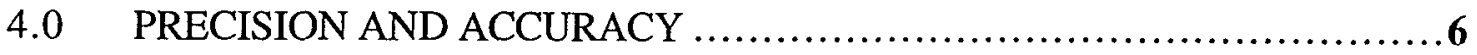

4.1 Calibration Requirements..................................... 7

4.2 Conditions which may adversely affect results ....................... 7

4.3 Sources of uncertainty and error to be controlled and measured..........8

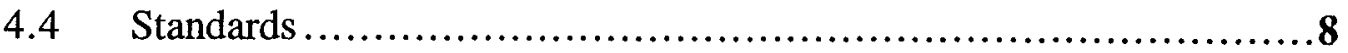

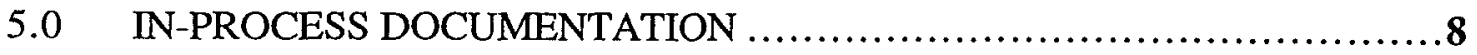

5.1 Data Recording and Data Reduction.................................8

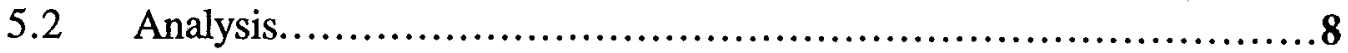

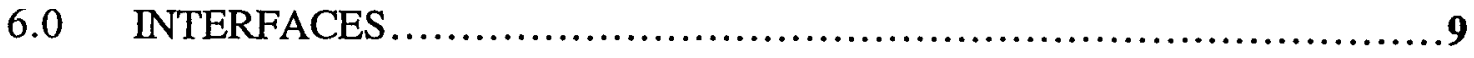

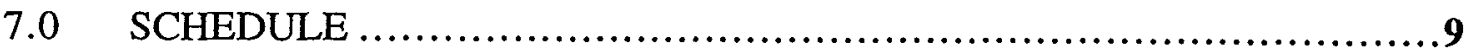

8.0 TECHNICAL IMPLEMENTING PROCEDURES ........................9

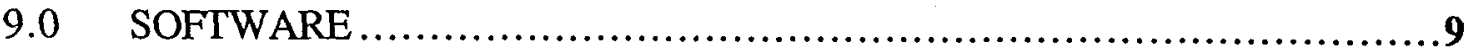

10.0 SPECIAL CASES ............................................................ 0

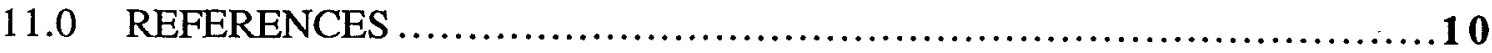

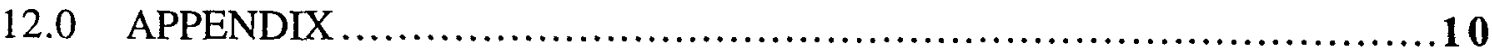




\section{LIST OF TABLES}

Page

Table 1 Minimum penetration depths measurable based on weight changes .....4

Table 2 Compositions of Candidate Container Materials ......................11 


\subsection{SCIENTIFIC INVESTIGATION PLAN}

This activity plan is prepared in accordance with Lawrence Livermore National Laboratory (LLNL) Yucca Mountain Project procedure 033-YMP-QP 3.0, "Scientific Investigation Control." This plan is written for Activity E-20-59, "Long Term Corrosion/Oxidation Studies under Controlled Humidity Conditions," which is part of the Scientific Investigation Plan (SIP) "Metal Barrier Selection and Testing" (SIP-CM-01, WBS \#1.2.2.5.1). This activity has been determined to be quality affecting.

\subsection{Activity Identity}

This activity is entitled "Long Term Corrosion/Oxidation Studies under Controlled Humidity Conditions," and has been assigned the activity number E-20-59, and is part of the Long Term Abiotic Laboratory Corrosion Testing described in the SIP "Metal Barrier Selection and Testing."

\subsection{Responsibilities}

Key personnel responsible for performing the work in this activity are:

Technical Area Leader, Engineered Barrier System Materials, and the Principal Investigator.

The TAL responsible for this activity will be Dr. R.D. McCright.

\subsection{SCOPE, PURPOSE, AND OBJECTIVES}

Independent of thermal loading scenarios, the waste packages at the potential repository at Yucca Mountain, Nevada will be exposed to environmental conditions where there is the possibility of significant water film formation occurring on the waste packages. Water films can cause aggressive "aqueous film electrochemical corrosion" on susceptible metals or alloys. Water film formation will be facilitated when relative humidities are high, when hygroscopic salts are present on the surfaces, when corrosion products are hygroscopic, and when particles form crevices with the surfaces (capillary effect). Also certain gaseous contaminants, such as, $\mathrm{NO}_{\mathrm{x}}$ and $\mathrm{SO}_{2}$, can facilitate water film formation. It should be noted that "water film" formation can occur at isolated spots (e.g. surface defects and salt particles) and need not cover the entire surface for electrochemical corrosion to occur.

This activity will characterize the long term corrosion of metal specimens at two nominal relative humidities $\left(50\right.$ and $85 \%$ ) and at $80^{\circ} \mathrm{C}$. Under the low relative humidity $(50 \%)$ condition, water film formation is expected to be limited and therefore aqueous film electrochemical corrosion is expected also to be limited. Under the high relative humidity $(85 \%)$ condition, significant water film formation 
is expected to occur under some test conditions, and subsequently aqueous film electrochemical corrosion will occur on susceptible materials.

The objective of this activity is to kinetically and mechanistically characterize the long-term corrosion and oxidation of candidate materials under constant humidity conditions. The metal specimens will be tested under a variety of conditions:

- "clean" surface - specimens that are free from significant surface contamination.

- coated with salts - specimens that are coated with salts that are characteristic of those contained in Yucca Mountain waters to simulate the effect of intermittent water contact leaving a residue or scale on the material's surface.

- in contact with a silica-based material - 'specimens that are in intimate contact with a silica-based material to simulate materials in contact with backfill or the eventual rock fall on the waste package.

- in contact with a cementitious material - specimens that are in contact with "invert" material to simulate the potential water film chemistry that may result from water contact with invert material or other cementitious material in the repository.

Different water film chemistries will result under each of these conditions. This will allow the characterization of the materials under various chemical and physical (creviced) conditions.

Specimens will be periodically removed from testing and will be characterized for corrosion at designated times. Total test duration is five years, possibly longer.

The results of this study will be used to assist:

1) in the activity "Recommendation of Container Materials (E-20-91),

2) in the Waste Package Performance Assessment Activities (SIP-PA02),

3 ) in the modeling activities "Low Temperature Oxidation Model Development" (E-20-75) and "General Aqueous Corrosion Model Development" (E-20-76), and

4) in the Near-Field Environment and Waste Package / Repository Design effort (many of the technical issues associated with the thermal output and arrangement of waste packages in the repository greatly influence the humidity levels around the container surface and their result on container performance). 


\subsection{ACTIVITY DESCRIPTION}

This activity will characterize the long-term corrosion of waste package candidate materials under constant temperature and humidity conditions. Two testing environments are planned. The test temperature will be nominally $80^{\circ} \mathrm{C}$, and test relative humidities will be nominally $50 \%$ and $85 \%$. All tests will be performed at atmospheric pressure. Long term is defined as times greater than 1-2 months. Kinetic and mechanistic information about the corrosion processes will be obtained.

Kinetic information will be obtained by periodically removing specimens from the test apparatus and weighing them. A decision will be made at that time as to whether the specimens will be returned to the test. Eventually the corrosion product will be removed from the specimen in order to determine the actual amount of material reacted.

There will be a sufficient number of specimens of each alloy to allow for removal and characterization of the corrosion at four designated time periods. Additional information on the reaction mechanisms will be obtained using surface analytical techniques to characterize the surface composition and structure of the corroded/oxidized metal in order to investigate variations due to different initial conditions. The surface analytical techniques will reveal complementary information on the mechanisms of oxidation and also on stability of the oxide structure. Techniques that may be employed include $x$-ray diffraction, microprobe analysis, Auger electron spectroscopy, x-ray photoelectron spectroscopy, infrared spectroscopy, and electron microscopy.

Nominal $2.5 \mathrm{~cm} \times 5.0 \mathrm{~cm}(1 " \times 2$ ") test specimens that are "clean", coated with salt, and in contact with a silica-based rock and invert material will be used. The spacers between specimens will give additional information on crevice corrosion.

Three classes of candidate metal alloys will be selected for assessment: corrosion resistant, intermediate corrosion resistant, and corrosion allowance. The corrosion resistant materials are the high nickel alloys, Alloys 625, C-22, and 825 , and the dilute titanium alloy, Ti-Grade 12. The intermediate corrosion resistant materials are Monel 400 and $\mathrm{Cu}-30 \% \mathrm{Ni}$. The corrosion allowance materials are low alloy and carbon steels: 1018 carbon steel, cast steel, and $2.25 \% \mathrm{Cr}-1 \%$ Mo steel. (See Section 3.4 "Materials" for further details.)

The primary focus of this activity will be on the corrosion allowance and intermediate corrosion resistant materials. These are the materials that are expected to be the most susceptible to the thin film aqueous electrochemical corrosion.

A conservative estimate of the minimum uniform penetration depths that can be measured in testing vary from 0.04 to $0.07 \mu \mathrm{m}$ depending on the alloy. This estimate assumes: uniform corrosion, specimen dimensions of $2.54 \mathrm{~cm} \times 5.08$ $\mathrm{cm} \times 0.31 \mathrm{~cm}(1 " \times 2 " \times 0.125 ")$ (surface area of $30.64 \mathrm{~cm}^{2}\left(4.75 \mathrm{in}^{2}\right)$ ), and a weight 
loss of $0.001 \mathrm{gm}$. The penetration depths are $0.07 \mu \mathrm{m}$ for the titanium alloys (density $4.54 \mathrm{~g} / \mathrm{cm}^{3}$ ) and $0.04 \mu \mathrm{m}$ for all the other alloys which have nearly the same densities $\left(7.9\right.$ to $\left.8.9 \mathrm{~g} / \mathrm{cm}^{3}\right)$.

Table 1. Minimum penetration depths measurable based on weight changes (see text)

\begin{tabular}{lcc}
\hline Alloy & Density $\left(\mathrm{g} / \mathrm{cm}^{3}\right)$ & $\begin{array}{c}\text { Minimum Penetration } \\
\text { Depth Measurable }(\mu \mathrm{m})\end{array}$ \\
\hline Ti (dilute alloys) & 4.54 & 0.07 \\
Alloy C-22 & 8.94 & 0.04 \\
Alloy 825 & 8.14 & 0.04 \\
Alloy 625 & 8.26 & 0.04 \\
Alloy 400 & 8.83 & 0.04 \\
Cu(30) - Ni(70) & 8.94 & 0.04 \\
Carbon steel & 7.86 & 0.04 \\
\hline
\end{tabular}

3.1 Technical and Readiness Reviews

No Technical or Readiness Reviews will be held for this activity

3.2 Hold points

The operation of the environmental chambers will be monitored on a continuous basis by the Principal Investigator to insure that the work is proceeding according to plan. If significant unanticipated problems arise, the Principal Investigator will inform the TAL. A joint decision will be made about the future course of action.

The progress of the test will be reported to the TAL periodically. If changes in project scope require that experimental work change direction, it is the responsibility of the TAL to communicate this to the Principal Investigator in writing.

In addition to the periodic progress reports, a yearly review of the progress of the activity is planned to ensure that the activity is proceeding according to the plan. 
3.3 Equipment

The equipment used to perform the thermogravimetric analysis studies include:

Environmental chambers that can obtain the required environments and maintain them for an extend period of time.

Relative humidity: $50 \%$ and $85 \%$

Temperature: $80^{\circ} \mathrm{C}$

The chambers will be identified in the scientific notebook.

Analytical balance that is capable of measuring to $0.001 \mathrm{mg}$ and has a load capacity of $200 \mathrm{~g}$. Balance must be user calibrated before use. Mettler Balance AT200 or equivalent is satisfactory.

Caliber that is capable of measuring to $0.01 \mathrm{~mm}$. Caliper must be usercalibrated before use.

Fowler Ultra-Cal Mark III Digital Caliper type instrument or equivalent is satisfactory.

\subsection{Materials}

The materials to be tested in this activity include most of the candidate metal alloys for the waste packages. For the Metal Barrier Selection and Testing Task purposes, the metallic alloy materials have been classified in three groups based on their corrosion properties: "corrosion resistant," "intermediate corrosion resistant," and "corrosion allowance." The "corrosion resistant" materials are the high nickel alloys, Alloys C-22, C4, 625, G-3, and 825, and the dilute titanium alloys, Ti-Grades 12 and 16. The "intermediate corrosion resistant" materials are Monel 400 and $\mathrm{Cu}$ $30 \% \mathrm{Ni}$. The "corrosion allowance" materials are low alloy and carbon steels: A516 carbon steel, A27 cast steel, and $2.25 \% \mathrm{Cr}-1 \%$ Mo steel. Table 2 contains the common names of the alloys, their Unified Numbering System identification number, and typical compositions.

Some of the materials are expected to have similar behavior under these test conditions; therefore, the number of material will be limited in this testing. The wrought carbon steel will be tested and not the cast steel. Alloy C-22 will be tested and not alloy C-4. Alloy G-3 will not be tested since its corrosion properties are expected to be intermediate between Alloys 825 and 625 . Only one of the titanium alloys will be tested.

All the materials to be tested in this activity are commercially available metal alloys, except for the newly developed Ti-Grade 16. However, TiGrade 16 is a dilute titanium alloy $(0.05 \mathrm{wt} \% \mathrm{Pd})$ and is expected to have 
corrosion properties similar to the higher Pd content Ti-Grade 7 (0.2 wt.\% $\mathrm{Pd})$ under most conditions, but at much less cost. Mechanical properties of Ti-Grade 16 are expected to be similar to those of commercial purity titanium (Ti-Grade 2).

Test specimens will be purchased commercial grade. The scientific notebook will contain the information on each metal alloy heat number, composition, and metallurgical condition. Otherwise the scientific notebook will reference the location of such information.

3.5 Special Environmental Conditions

The tests will be performed in laboratory air. Relative humidities will be controlled at 50 and $85 \%$, and the test temperature will be $80^{\circ} \mathrm{C}$. All testing will be performed at atmospheric pressure.

3.6 Special Training/Qualification Requirements

Qualifications of the Principal Investigator(s) and technicians are specified by the TAL. Only personnel trained to appropriate quality procedures and any other procedures of the Yucca Mountain Site Characterization Project will be allowed to participate in this activity.

3.7 Quality Assurance Program

This activity is to be conducted in support of "Metal Barrier Selection and Testing," as outlined in CN SIP-CM-01, Rev. 3. The study will be conducted subject to the provisions of applicable quality assurance procedures. Specific records are generated by these quality procedures; these records are the "de facto" evidence of selection and use of the procedures.

\subsection{Activity Closeout}

The final product of this activity will be a LLNL UCRL report documenting all results. Supporting documentation such as scientific notebooks and technical review comments will be retained by the responsible individual until the document package is transferred to the LLNLYMP Local Records Center at the conclusion of the activity.

\subsection{PRECISION AND ACCURACY}

There are two categories of measurement and analysis for this activity: the test parameters, and specimen characterization both before and after testing. During testing the temperature and relative humidity of the environment will be monitored continuously. For the purposes of this testing, the test apparatus (humidity chamber) feedback control will be used to control temperature and 
humidity. Periodic monitoring and recording of the temperature and humidity readout of the apparatus will be performed.

Specimen characterization will require the use of a caliper and an analytical balance. The caliber (see equipment) is capable of measuring to 0.001 in or $0.01 \mathrm{~cm}$ with an accuracy of \pm 0.0005 in or $0.005 \mathrm{~cm}$. The analytical balance (see equipment) is capable of measuring to $0.0001 \mathrm{~g}$ with an accuracy of \pm $0.0001 \mathrm{~g}$. Conservatively, uniform penetration depths of $0.1 \mu \mathrm{m}$ can be determined with these measurements.

Post-test analysis of a test specimen will include a characterization of the surface oxidation layer. Analytical techniques could include, but are not limited to $x$-ray diffraction, Auger electron spectroscopy, microprobe analysis, electron microscopy, infrared spectroscopy, and $x$-ray photoelectron spectroscopy. The exact post-test analyses used will depend on the condition of the as-exposed specimens and will be indicated in the appropriate scientific notebooks.

\subsection{Calibration Requirements}

The instruments for measuring and weighing the test specimens will be user calibrated before using; the expected instruments are calipers and an analytical balance. Calibration will be performed with NIST traceable gage blocks and weights. Calibration will be documented either in the scientific notebook or on electronic media.

Temperature and humidity sensors that have been calibrated to NIST traceable standards will also be emplaced in the chambers. These sensors will serve two purposes: 1) as a check on the chamber control sensors and 2) to monitor the uniformity of conditions within the chamber. The independent sensors can be removed from the chambers and calibrated when necessary.

Since this is a long-term continuous test and removing the chamber control sensors would cause an interruption of the test, the sensors will not be required to be calibrated unless the apparatus operator determines that they are malfunctioning. An indication of malfunctioning may be significant difference in the readings between an independent sensor that has been recently calibrated.

\subsection{Conditions which may adversely affect results}

Any occurrence which results in the chamber temperature falling below the dew point could adversely affect the results. This would result in water condensation, which would affect the corrosion processes. Administrative procedures will be employed to ensure that the relative humidity and temperature are at acceptable values when access into the chamber is required. 
Loss of power to the chamber may or may not result in condensation of water within the chamber. Any loss of power will be noted in the scientific notebook.

4.3 Sources of uncertainty and error to be controlled and measured

Any test measurement from a single specimen of a specific alloy may give anomalous results, therefore multiple specimens of a specified alloy will be used to ensure consistency.

\subsection{Standards}

The standards to be followed or used for guidance are listed below.

ASTM G 46-94, "Guide for Examination and Evaluation of Pitting Corrosion"

ASTM G 1-90, "Practice for Preparing, Cleaning, and Evaluating Corrosion Test Specimens"

ASTM G 50-76 (1992), "Practice for Conducting Atmospheric Corrosion Tests on Metals"

\subsection{IN-PROCESS DOCUMENTATION}

Documentation to be generated during the conduct of this activity will include scientific notebooks and may also include data record sheets, raw data, progress reports and the final report.

After completion of the activity, a LLNL UCRL report will be written. Interim LLNL UCRL reports may also be written if deemed appropriate.

\subsection{Data Recording and Data Reduction}

Relative humidity and temperature data will be recorded manually into the scientific notebook or on electronic media.

Specimens will be measured and weighed before and after testing. Data recording and reduction will be done through the use of scientific notebooks, and electronic databases or spreadsheets.

\subsection{Analysis}

Analysis of the data will include a graphical analysis of the data in order to determine a functional form of the corrosion rate (e.g. linear or parabolic). The corrosion product formed will be characterized by surface analytical techniques in order to determine the composition and 
structure of the corrosion product formed. This analysis will aid in determining the corrosion mechanisms.

\subsection{INTERFACES}

The information obtained in this activity will assist activities in the following technical areas:

1) Metal Barrier Selection and Testing (SIP-CM-01)

R.D. McCright, TAL, Metal Barrier Selection and Testing

2) Waste Package Performance Assessment activities (SIP-PA-2) W. Halsey, TAL, Performance Assessment

After initiation of the experimental work, progress reports from this activity will be sent to TALs identified with the above SIP and activities. If deemed appropriate, meetings of cognizant PIs to discuss the activity's results will be conducted.

\subsection{SCHEDULE}

Testing will begin in FY97 and continue for at least the next five years. Specimens will be removed periodically for analysis. The specimens are independently removable with minimum disruption of the testing.

\subsection{TECHNICAL IMPLEMENTING PROCEDURES}

There are no Technical Implementing Procedures (TIPs) planned for the performance of this activity.

\subsection{SOFTWARE}

The commercial software that will be utilized in this activity are:

Igor (Wavemetrics) or similar programs for graphing and data analysis.

Excel (Microsoft) or similar spreadsheet and graphing programs for displaying ICF control and process parameters on a monitor.

Any software that will be used for analysis of the test data will be identified and discussed in the activity's Scientific Notebook. 


\subsection{SPECIAL CASES}

No subcontractors are involved in this activity.

\subsection{REFERENCES}

ASTM G 46-94, "Guide for Examination and Evaluation of Pitting Corrosion" ASTM G 1-90, "Practice for Preparing, Cleaning, and Evaluating Corrosion Test Specimens"

ASTM G 50-76 (1992), "Practice for Conducting Atmospheric Corrosion Tests on Metals"

\subsection{APPENDIX}

There are no appendices. 
Table 2. Compositions of Candidate Container Materials.

\begin{tabular}{|c|c|c|c|}
\hline UNS number & $\begin{array}{l}\text { Common or Commercial } \\
\text { Name }\end{array}$ & ASTM Number & Nominal Composition (weight \%) \\
\hline N08825 & $\begin{array}{l}\text { Alloy } 825 \\
\text { Incoloy } 825\end{array}$ & B 424 (plate) & $\begin{array}{l}\text { Ni 38.0-46.0; Cr 19.5-23.5; Mo } 2.5- \\
\text { 3.5; Fe balance; Cu 1.5-3.0; Ti 0.6- } \\
\text { 1.2; Mn } 1.0 \text { max; C 0.05 max; Si 0.5 } \\
\text { max; S } 0.03 \text { max; Al 0.2 max }\end{array}$ \\
\hline N06030 & $\begin{array}{l}\text { Alloy G-30, } \\
\text { Hastelloy G-30 }\end{array}$ & B 582 (plate) & $\begin{array}{l}\text { Ni balance; Cr 28.0-31.5; Mo 4.0-6.0; } \\
\text { Fe 13.0-17.0; W 1.5-4.0; Co 5.0 max; } \\
\text { Cu 1.0-2.4; Nb+Ta 0.3-1.5; Mn } 1.5 \\
\max \text { C } 0.03 \max ; \text { Si } 0.8 \max ; \text { S } 0.02 \\
\max ; \text { P 0.04 } \max \end{array}$ \\
\hline N06625 & $\begin{array}{l}\text { Alloy } 625 \\
\text { Inconel } 625\end{array}$ & B 443 (plate) & 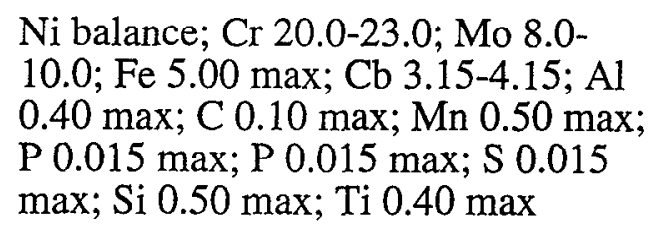 \\
\hline N06455 & $\begin{array}{l}\text { Alloy C-4, } \\
\text { Hastelloy C-4 }\end{array}$ & B 575 (plate) & $\begin{array}{l}\text { Ni balance; Cr } 14.0-18.0 ; \text { Mo } 14.0- \\
17.0 ; \text { Fe } 3.0 \max \text {; Co } 2.0 \max ; \text { Mn } 1.0 \\
\max \text { C } 0.015 \max ; \text { Si } 0.8 \max \text {; Ti } 0.7 \\
\max \text { S } 0.03 \max ; \text { P } 0.04 \max \end{array}$ \\
\hline N06022 & $\begin{array}{l}\text { Alloy C-22, } \\
\text { Hastelloy C-22 }\end{array}$ & B 575 (plate) & $\begin{array}{l}\text { Ni balance; Cr 20.0-22.0; Mo } 12.5- \\
\text { 14.5; Fe 2.0-6.0; W 2.5-3.5; Co } 2.5 \\
\text { max; Mn 0.5 max; C } 0.015 \max ; \mathrm{Si} \\
0.8 \max ; \text { V0.35 max; S } 0.02 \max ; \mathrm{P} \\
0.02 \max \end{array}$ \\
\hline $\mathrm{R} 53400$ & Ti-Grade 12 & B 265 Grade 12 & $\begin{array}{l}\text { Ni 0.6-0.9; Mo 0.2-0.4; N } 0.03 \max \\
\text { C } 0.08 \text { max; H } 0.015 \max ; \text { Fe } 0.3 \\
\text { max; O } 0.25 \text { max; Ti balance }\end{array}$ \\
\hline none to date & Ti-Grade 16 & none to date & $0.05 \mathrm{Pd}$; Ti balance \\
\hline
\end{tabular}


Table 3.4.1. Compositions of Candidate Container Materials (cont'd).

\begin{tabular}{|c|c|c|c|}
\hline UNS number & $\begin{array}{l}\text { Common or Commercial } \\
\text { Name }\end{array}$ & ASTM Number & Nominal Composition (weight \%) \\
\hline N04400 & $\begin{array}{l}\text { Alloy } 400 \text {, } \\
\text { Monel } 400\end{array}$ & B 127 (plate) & $\begin{array}{l}\mathrm{Ni} 63.0 \min ; \mathrm{Cu} 28.0-34.0 ; \mathrm{Fe} 2.5 \\
\max ; \mathrm{Mn} 2.0 \mathrm{max} ; \mathrm{C} 0.03 \max ; \text { Si } 0.5 \\
\max ; \mathrm{Si} 0.5 \max ; \text { S } 0.024 \max \end{array}$ \\
\hline C71500 & $\begin{array}{l}70-30 \text { copper-nickel, } \\
\text { CDA } 715\end{array}$ & B 171 (plate) & $\begin{array}{l}\text { Ni } 29.0-33.0 ; \text { Cu balance; Mn } 1.0 \\
\max ; \mathrm{Pb} 0.02 \text { max; Fe } 0.4-1.0 ; \mathrm{Zn} 0.5 \\
\max ; \mathrm{C} 0.05 \text { max; P } 0.02 \text { max; S } 0.02 \\
\max \end{array}$ \\
\hline K01800 & 1018 Carbon Steel & A 516 (Grade 55) & $\begin{array}{l}\text { C } 0.18 \text { max; Mn 0.55-0.98; P } 0.035 \\
\text { max; S } 0.04 \max ; \text { Si } 0.13-0.45 ; \text { Fe } \\
\text { remainder }\end{array}$ \\
\hline J02501 & Centrifugally Cast Steel & A 27 (Grade 70-40) & $\begin{array}{l}\mathrm{C} 0.25 \max ; \mathrm{Mn} 1.2 \max ; \mathrm{P} 0.050 \\
\text { max; } \mathrm{S} 0.060 \max ; \mathrm{Si} 0.80 \text { max; Fe } \\
\text { remainder }\end{array}$ \\
\hline $\mathrm{K} 21590$ & 2.25Cr - 1Mo Alloy Steel & A 387 (Grade 22) & $\begin{array}{l}\text { C } 0.15 \text { max; Mn } 0.3-0.6 ; \mathrm{P} 0.035 \\
\max ; \mathrm{S} 0.035 \max ; \mathrm{Si} 0.5 \max ; \mathrm{Cr} \\
2.00-2.50 ; \text { Mo } 0.90-1.10 ; \mathrm{Fe} \\
\text { remainder }\end{array}$ \\
\hline
\end{tabular}

